\title{
Tip 2 Diyabetli Obez Bireylerin Yeme Farkındalığı Düzeyleri ile Metabolik Parametreleri Arasındaki İlişki
}

\author{
Fatma Kübra SAYIN ®凶, Sevim KUŞDEMİR ๑, Gizem BÜYÜKSÜTÇÜ ๑, \\ Şeyma Merve ÇETINKAYA ๑, Sedanur SEYFİ ๑, Esra ZEREN ๑
}

Necmettin Erbakan Üniversitesi, Sağlık Bilimleri Fakültesi, Beslenme ve Diyetetik Bölümü, Konya

Bu makaleye yapılacak atıf: Sayın FK, Kuşdemir S, Büyüksütçü G, Çetinkaya ŞM, Seyfi S, Zeren E. Tip 2 Diyabetli Obez Bireylerin Yeme Farkındalığı Düzeyleri ile Metabolik Parametreleri Arasındaki İlișki. Türk Diyab Obez 2019;2: 93-98.

\begin{abstract}
ÖZET
Amaç: Diyabetik popülasyonda yeme farkındalığını araştıran çok az yayınlanmış çalışma vardır ve yeme farkındalığı ile metabolik parametreler arasındaki ilişkiyi değerlendiren bir çalışma yoktur; Bu nedenle, bu çalışmanın amacı, tip 2 diyabetli obez bireyler arasında yeme farkındalığının beden kütle indeksi (BKİ) ile bazı metabolik parametreler arasındaki ilişkilerini incelemektir.

Gereç ve Yöntemler: Bu kesitsel çalışmada, Necmettin Erbakan Üniversitesi Meram Tip Fakültesi Hastanesi Diyet Kliniğine başvuran 94 tip 2 diabetes mellitus hastasının dosyaları incelendi. Katılımcılar, beş alt boyuttan (disinhibisyon, farkındalık, dış etkenler, duygusal cevap ve dikkat dağılması) oluşan 30 maddelik yeme farkındalığ profili gibi metabolik parametreleri kaydedildi ve analiz edildi.

Bulgular: Çalışma popülasyonumuzda hastaların \% 26.6’sı $(n=25)$ erkek,\% 73.4’ü $(n=69)$ kadındı. Korelasyon analizi sonuçları, düşük yeme farkındalığı puanlarının, yüksek BMI, kilo, glukoz ve üre seviyeleri ile anlamlı şekilde ilişkili olduğunu göstermiştir.

Sonuç: Obezite ve diyabet hastalıklarını değerlendirirken hastaların yeme farkındalık düzeylerinin antropometrik verilerle ve metabolik parametrelerle etkileşim içinde olabileceği göz önünde bulundurulmalıdır. Bu hastalıkların yönetilmesinde yeme farkındalığı oluşturma üzerinde durulması gereken bir konudur.
\end{abstract}

Anahtar Sözcükler: Tip 2 diabetes mellitus, Obezite, Yeme farkındalı̆̆ı, Beden Kitle İndeksi

\section{The Relationship Between Eating Awareness Levels and Metabolic Parameters in Obese Individuals with Type 2 Diabetes}

\begin{abstract}
Aim: There are little published data exploring mindful eating in diabetic population, and no work evaluating the relationship between mindful eating and metabolic parameters; thus, the purpose of this study was to examine the relationships of eating awareness to BMI and metabolic parameters among of obese individuals with type 2 diabetes

Material and Methods: In this cross-sectional study files of 94 type 2 diabetes mellitus patients who applied to Necmettin Erbakan University Meram Medical Faculty Hospital Diet Clinic were examined. Participants completed the 30-item Mindful Eating Questionnaire, consisting of five subscales (Disinhibition, Awareness, External Cues, Emotional Response, and Distraction) and data about height, weight, and sociodemography, duration of disease and metabolic parameters like fasting blood glucose, lipid profile, were recorded and analyzed.

Results: In our study population, $26.6 \%(n=25)$ of the patients were male and $73.4 \%(n=69)$ were female. Correlation analysis results demonstrated that lower mindful eating scores were associated significantly with higher BMI, weight, glucose and urea levels.

Conclusion: When evaluating obesity and diabetes diseases, it should be considered that mindful eating levels of patients may interact with anthropometric data and metabolic parameters. In order to manage these diseases, mindful eating is an issue that needs to be emphasized.
\end{abstract}

Key Words: Type 2 diabetes mellitus, Obesity, Eating awareness

ORCID: Fatma Kübra Sayın / 0000-0002-2006-0626, Sevim Kuşdemir / 0000-0003-0367-4054, Gizem Büyüksütçü / 0000-0002-0174-6686, Şeyma Merve Çetinkaya / 0000-0002-3409-7547, Sedanur Seyfi / 0000-0002-4135-2147, Esra Zeren / 0000-0003-4486-0072 


\section{GİRIŞ}

Obezite, enerji yoğunluğu fazla olan yiyeceklerin tüketimi ve azalmış fiziksel aktivitenin sonucu olarak aşırı ve anormal yağ birikimi ile karakterize karmaşık bir tıbbi hastalıktır (1). Obezitenin artmasındaki sebeplere bakıldığında genetik aktarımlar ve enerji yoğunluğu fazla olan yiyeceklerin ulaşılabilir hale gelmesi ile sedanter yaşam tarzını kapsayan çevresel faktörler sayılabilir. Ülkemizde yapılan Türkiye Diyabet Epidemiyolojisi (TURDEP-I ve TURDEP-II) çalışmalarına göre 1997-1998 yılları arasında obezite prevelansı kadınlarda \%32.9, erkeklerde \%13.2 iken 2010 yılında prevelans artmış ve kadınlarda \%44.2, erkeklerde $\% 27.3$ olarak bulunmuş olup, Türkiye'de toplam obezite sıklığ 1 ise \%32 olarak belirtilmiştir (2).

Dünya Sağlık Örgütü’ne göre obezite, son 35 yılda iki katına çıkmış olan bir sağlık sorunudur ve birçok kronik hastalığa sebep olur. Vücut yağ dağılımı ve toplam yağ oranını sorumlu olduğu hastalıkların başında, diyabet ve kardiyovasküler hastalıklar yer almaktadır (3).

Obezite, Tip 2 diyabete çoğunlukla eşlik etmekle beraber, kişide diyabet gelişeceğini belirleyen önemli bir risk faktörüdür. Ayrıca araştırmalar özellikle abdominal obezite ile insulin direnci arasında sıkı ilişki varlığını ortaya koymaktadır (4). Diabetes mellitus (DM) insülinin tamamen kaybı veya insüline karşı gelişen direnç nedeniyle gelişen ve hiperglisemi ile karakterize bir hastalıktır $(5,6)$. Tip 2 diyabet prevelansı önlem alınmadığı sürece, özellikle gelişmekte olan toplumlarda giderek yükselmektedir $(7,8)$.

Yeme davranışının vücut ağırlığı ve beden kütle indeksi (BKI) dolayısıyla obezite ile olan derin ilişkisi yıllardır bilinmektedir. Obezitenin tedavisinde kullanılan en yaygın yöntem olan enerji kısıtlaması uzun süreli uygulamalarda başarılı olmamaktadır (9). Diyet tedavisinin yanında yeme farkındalığı kazanarak davranış değişikliğinin de eklenmesi ile vücut ağırlığının yönetimi ve buna bağlı yaşam boyu yüksek hayat kalitesi sağlanabilmektedir (10). Yeme farkındalığının kazandırılması ile sağlıklı ve kalıcı bir beslenme tedavisi uygulanabilmektedir $(11,12)$.

Yeme farkındalığı ne yediğimiz ve bize nasıl hissettirdiği konusunda farkındalık sağlayan zihin ile beden arasındaki bağlantı olarak tanımlanır (13). Basit bir tanımlamayla tüketilen besine ya da içeceğe odaklanarak yeme, olarak özetlenebilir. Yeme farkındalığının detaylı tanımlamasından önce farkındalık kavramına değinilmelidir. Bilinçli farkındalık, şu ana kayıtsız şartsız bilinçli olarak dikkatini vermeyi içeren bir farkındalık, olarak ifade edilebilir (14). 'Mindfullness' sözcügünün tam karşılığı olan 'Bilinçli Farkındalık' yeme davranışlarına yansıtıldığında 'Farkına Vararak Yeme' ya da 'Yeme Farkındalığı' olarak söylenebilir (15).
Yeme farkındalığı; ne yenildiğinden çok, nasıl ve neden yeme davranışının oluştuğunu fark ederek, fiziksel açlık-tokluk kavramını içselleştirip duygu ve düşüncelerin etkisinin farkında olarak, çevresel etmenlerden etkilenmeden, besin seçimlerini yargılamadan, burada ve şu anda tüketilecek olan besine odaklanarak yeme olarak tanımlanmıştır. Yeme farkındalığı kapsamında özellikle porsiyon kontrolünü sağlama, duygusal yemeyi engelleme, aşırı yemeyi durdurabilme, gibi içsel ve dışsal faktörler ile vücut ağırlığı yönetiminde önemli rol oynamaktadır (16).

Daha önceki araştırmalara dayanarak, obezitenin negatif duygularla yüksek oranda ilişkili olduğunu söyleyebiliriz. Öfke, kaygı, üzüntü veya depresyon yeme alışkanlıklarımızın oluşmasına katkıda bulunur. İştahın artmasına ve daha yüksek kalorili yiyeceklerin aranmasına neden olabilir, böylece bireyin ruh hali ile tüketim arasındaki ilişkiyi daha iyi anlayamadığı bir zincirleme reaksiyon oluşturur $(17,18)$. Ayrıca düşük yeme farkındalığına sahip olmanın yanlış beslenme kaynaklı metabolik risk faktörlerini artırması mümkündür. Diyabetin, diyet yönetimiyle ve bir çok metabolik risk faktörüyle ilişkili bir hastalık olması ilgimizi çekmiştir. Diyabetik popülasyonda yeme farkındalığını araştıran çok az yayınlanmış çalışma vardır ve bu grupta yeme farkındalığı ile metabolik parametreler arasındaki ilişkiyi değerlendiren çalışmaya rastlayamadık; Bu nedenle, tip 2 diyabet ile yaşayan obez bireylerin yeme farkındalık düzeylerini bu amaçla geliştirilmiş bir ölçek kullanarak belirlemeyi ve bu sonuçların metabolik risk faktörleri ile ilişkisini değerlendirmeyi amaçladık.

\section{GEREÇ ve YÖNTEMLER}

$\mathrm{Bu}$ çalışma Konya ilinde Konya Necmettin Erbakan Üniversitesi Meram Tip Fakültesi Hastanesi Diyet Polikliniğine başvuran araştırmaya katılmaya gönüllü, 18 yaş üzeri yetişkin 150 katılımcının yeme farkındalığının metabolik bulguları üzerine etkisini saptamak için planlanmıştır.

Araştırmaya katılan bireylerin genel bilgilerini, yeme farkındalığı skorlarını saptamak amacıyla soruşturma yöntemi kullanılarak anket uygulanması planlanmıştır. Çalışma anketi 3 bölümden oluşmaktadır.

Anketin birinci bölümünde katılımcilara ait cinsiyet, yaş, boy uzunluğu, vücut ağırlığı, beslenme alışkanlığı gibi genel bilgiler sorgulanmıştır. İkinci bölümde bireylerin yeme farkındalığı sorgulanmıştır. Bu amaçla revize edilmiş Yeme Farkındalığı Ölçeği (YFÖ-30) kullanılmıştır. Anketin üçüncü bölümünde ise daha önce alınmış biyokimyasal değerleri sorgulanmıştır. 
Framson ve arkadaşları tarafından 2009 yılında geliştirilen özgün adı Mindful Eating Questionnare (MEQ) olan ölçek ile yeme davranışı, farkındalığı ve duygusal durum arasında ilişkilendirmeler dikkatlice sorgulanabilmektedir. Ölçeğin orjinalinde yer alan maddeler 4'lü likert skalası ile değerlendirilmektedir (1:hiç/nadiren, 2:bazen, 3: sık sık, 4: genellikle/her zaman) ve 28 soruluk likertin etki faktörleri: disinhibisyon, farkındalık, dış etkenler, duygusal cevap ve dikkat dağılması şeklindedir (11).Yeme Farkındalığı ölçeğinin Türkçeye uyarlama çalışması Köse ve ark. tarafindan yapılmıştır (20). Türkçeye uyarlama çalışması sırasında kapsam geçerliliği için uzman görüşleri doğrultusunda ölçeğe yeni maddeler eklenmiştir bu şekilde Yeme farkındalığı ölçeği (YFÖ-30) son halini almıştır (20).

Olguların biyometrik ölçümleri (boy, kilo ve bel çevresi),son tetkiklerindeki açlık kan şekeri (AKŞ), HbA1c, lipit profili [trigliserit (TG), yüksek dansiteli lipoprotein kolesterolü (HDL-k), düşük dansiteli lipoprotein kolesterolü (LDL-k), total kolesterol (TK)], üre, kreatinin, ürik asit, sodyum, potasyum, klor, kalsiyum, fosfor, magnezyum, total protein, albümin, kaydedilmiştir.

Çalışmada yer alan tanımlayıcı istatistikler ortalama, standart sapma, minimum ve maksimum değerleriyle gösterildi. Sürekli değişkenlerin normal dağılıma uygunluğu Shapiro Wilk testi ile incelendi. Yeme farkındalığı skorları ile metabolik parametreler arasındaki ilişkiyi saptamak için
Spearman's korelasyon analizi kullanıldı. Çalışmadaki tüm analizlerde $\mathrm{p}$ değeri 0,05 'in altındaki sonuçlar istatistiksel olarak anlamlı kabul edildi.

\section{BULGULAR}

Necmettin Erbakan Üniversitesi, Konya Meram Tip Fakültesi Hastanesi'nde yapilan çalışmada 18 yaş ve üzeri $25(\% 26,6)$ 's1 erkek, $69(\% 73,4)$ 'ü kadın toplamda 94 yetişkin gönüllü birey üzerinde çalışılmıştır. Katılımcı grubumuzun yaş aralı̆̆ 25 ile 78 arasında değişmekte olup ortalama yaş 58' dir. Erkek katılımcıların yaş ortalaması 64 , kadın katılımcıların yaş ortalaması ise 56'dır. Vücut ağırlığı aralığ $64 \mathrm{~kg}$ ile $155 \mathrm{~kg}$ arasında değişmekte olup ortalama vücut ağırlı̆̆ 94 kg'dır. Erkek katılımcıların vücut ağırlığ ortalaması $97.2 \mathrm{~kg}$ iken kadın katılımcıların vücut ağırlığı ortalaması $92.7 \mathrm{~kg}$ 'dır. BKI ise minimum $30 \mathrm{~kg} / \mathrm{m}^{2}$ ile maksimum $53.3 \mathrm{~kg} / \mathrm{m}^{2}$ arasında değer almaktadır. Ortalama BKI değeri $35.9 \mathrm{~kg} / \mathrm{m}^{2}$ 'dir. Cinsiyete göre ortalama BKI değerlerini incelediğimizde erkeklerin ortalama BKI değeri $33.6 \mathrm{~kg} / \mathrm{m}^{2}$ iken kadınların ortalama BKI değeri $36.7 \mathrm{~kg} /$ $\mathrm{m}^{2}$ 'dir (Tablo 1).

Yeme farkındalığı puanı minimum 62 iken maksimum 112 puan değerini almaktadır. Ortalama yeme farkındalı̆̆ 1 puanı ise 82'dir. Açlık kan şekeri değeri minimum $70.6 \mathrm{mg} /$ dL ile maksimum $664 \mathrm{mg} / \mathrm{dL}$ iken ortalama değer $178.4 \mathrm{mg} /$ dL'dir.

Tablo 1: Hastaların yaş, Yeme Farkındalığı Ölçeği (YFÖ-30) ve metabolik parametreleri değerleri.

\begin{tabular}{lcccc}
\hline & Ort. & Standart sapma & Minimum & Maksimum \\
\hline Yaș (yıl) & 58,36 & 13,50 & 25,00 & 78,00 \\
\hline Vücut ağırlı̆̆ı (kg) & 94,08 & 16,90 & 64,00 & 155,00 \\
\hline BKİ (kg/m2) & 35,94 & 5,26 & 30,00 & 53,30 \\
\hline Yeme Farkındalı̆̆ı Puanı & 82,04 & 10,59 & 62,00 & 112,00 \\
\hline AKȘ (mg/dl) & 178,44 & 93,43 & 70,60 & 664,00 \\
\hline Üre & 47,33 & 39,28 & 8,00 & 209,00 \\
\hline Kreatinin & 1,10 & 0,70 & 0,50 & 6,14 \\
\hline Ürik Asit & 8,20 & 17,68 & 1,90 & 137,00 \\
\hline Sodyum & 1,37 & 15,37 & 4,78 & 152,00 \\
\hline Potasyum & 4,45 & 0,48 & 2,95 & 5,95 \\
\hline Kalsiyum & 9,56 & 3,33 & 7,48 & 38,00 \\
\hline Trigliserid (mg/dl) & 1,86 & 101,96 & 77,00 & 779,00 \\
\hline Total Kolesterol (mg/dl) & 1,89 & 44,64 & 27,90 & 288,00 \\
\hline LDL-K (mg/dl) & 1,29 & 103,82 & 41,10 & 874,00 \\
\hline HDL-K (mg/dl) & 48,21 & 42,33 & 22,90 & 368,00 \\
\hline Albümin & 8,48 & 12,06 & 2,89 & 47,90 \\
\hline
\end{tabular}

AKŞ: Açlık kan şekeri, BKİ: Beden kütle indeksi 
Bireylerin yeme farkındalığ 1 ve diğer parametreler arasındaki ilişki değerlendirildiğinde, vücut ağırlığı ve yeme farkındalığı puanı arasında negatif yönde düşük düzeyde anlamlı bir ilişki saptanmıştır $(\mathrm{r}=-0,285, \mathrm{p}=0.006)$. Benzer şekilde BKİ ve yeme farkındalığı puanı arasında negatif yönde düşük düzeyde anlamlı bir ilişki vardır $(r=-0,337$, $\mathrm{p}=0,001)$. Yine korelasyon analizleri sonucunda görülmüştür ki, katılımcıların yeme farkındalık puanları arttıkça AKŞ, üre ve kreatinin düzeyleri düşmektedir (sırasıyla $\mathrm{r}=-0.217$, $\mathrm{p}=0.010 ; \mathrm{r}=-0.346, \mathrm{p}=0.001 ; \mathrm{r}=-0.297, \mathrm{p}=0.004)$. Ayrica yaş ve yeme farkındalı̆̆ puanı arasında negatif yönde düşük düzeyde anlamlı bir ilişki vardır $(r=-0,259, \mathrm{p}<0,05)$. Kalsiyum ve yeme farkındalığı puanı arasında pozitif yönde düşük düzeyde anlamlı bir ilişki vardır $(r=0,238, p<0,05)$.

Trigliserit, total kolesterol, LDL, HDL, albümin, sodyum, potasyum değerleri ile yeme farkındalığı puanı arasında anlamlı bir ilişki bulunmamıştır (Tablo 2).

Ayrıca korelasyon sonucunda yeme farkındalığı puanları ile ana öğün sayısı ve ara öğün sayısı arasında anlamlı bir ilişki bulunmamıştır $(p>0,05)$. Bu sonuca göre yeme farkındalığının artması öğün sayısı ve ara ögün sayısında bir artışa yol açmamaktadır.

\section{TARTIŞMA}

Farkındalık kavramı son yıllarda davranışsal tıpta ve vücut ağırlığı düzenlenmesinde sıklıkla kullanılan bir terim olmasının yanında diyabet yönetiminde de başvurulması gereken bir yoldur. Diyabet hastaları arasinda yapilan araştırmalar, farkındalık odaklı yaklaşımın depresif semptomları, kaygıyı, diyabetle kaynaklı sıkıntıları ve sağlıkla ilgili yaşam kalitesini iyileştirdiğini göstermiştir (20-22). Fakat farkındalık yaratma müdahalelerinin hemoglobin A1C düzeyleri üzerindeki etkisi çelişkilidir, bazı çalışmalarda anlamlı bir değişim görülmezken, bazılarında hemoglobin $\mathrm{A} 1 \mathrm{C}$ düzeyleri anlamlı bir şekilde düzelmiştir.

Genelde farkındalık eğitimi, vücut ağırlığında ve abdominal yağlanmada (9) iyileşmelerle ilişkilendirilmiştir $(23,24)$. Bizim çalışmamızda yeme farkındalığı ile AKŞ, üre ve kreatinin düzeyleri arasında ters yönde anlamlı bir ilişki bulunmuştur. Yeme farkındalığı düzeyinin artması ile sebze ve meyve tüketimini artırma, enerji yoğun gıda alımını azaltma ve atıştırma alışkanlıklarını azaltma sureti ile beslenme davranışlarını iyileştirebilir $(25,26)$.

Ayrıca yeme farkındalığı, daha sağlıklı beslenme davranışlarını teşvik edebilir. Yeme farkındalığı, genellikle otomatik ve dikkatsizce yiyecek tüketimini uyaran duygusal uyarıcılara cevap vermeyi kesintiye uğratabilir (27). Otomatik yemek, duygusal, dürtüsel ve alışkanlıktan dolayı yemek yemeyi içerebilir (28). Bireyin yeme
Tablo 2: Katılımcıların Yeme Farkındalığı Ölçeği (YFÖ30) skorları ile kan parametreleri arasındaki korelasyon sonuçları.

\begin{tabular}{|c|c|c|}
\hline & $\mathbf{r}$ & p \\
\hline Vücut ağırlığı (kg) & -0.285 & $0.006^{*}$ \\
\hline BKİ (kg/m2) & -0.337 & $0.001^{*}$ \\
\hline Yaş (yıl) & -0.259 & $0.008^{*}$ \\
\hline AKŞ (mg/dl) & -0.217 & $0.010^{*}$ \\
\hline Üre & -0.346 & $0.001^{\star}$ \\
\hline Kreatinin & -0.297 & $0.004^{*}$ \\
\hline Sodyum & 0.165 & 0.138 \\
\hline Potasyum & 0.013 & 0.903 \\
\hline Kalsiyum & 0.238 & 0.038 \\
\hline Trigliserid (mg/dl) & 0.059 & 0.629 \\
\hline TotalKolesterol (mg/dl) & 0.123 & 0.323 \\
\hline LDL-K (mg/dl) & 0.103 & 0.416 \\
\hline HDL-K (mg/dl) & 0.160 & 0.195 \\
\hline Albümin & 0.201 & 0.108 \\
\hline
\end{tabular}

Anlamlllık düzeyi $\mathrm{p}<0.05$ dir.

farkındalığını uygulama ile geliştirmesi uyarılara hızlı tepki vermesini önleyebilir ve daha kontrollü bir yeme sürecinin gerçekleşmesini sağlayabilir.

Yaptığımız çalışmanın sonucuna göre ise katılımcıların YFÖ-30 ortalama puanı $82.04 \pm 10.59$ ve en az alınan puan 62, en fazla alınan puan ise 112 olarak bulunmuştur. Ayrıca bu çalışmada yeme farkındalı̆̆ı puanlarının yaş ile ters orantılı olduğu görülmüştür. Tip 2 diyabet hastalarında erken yaşlarda diyetle ilgili konulara daha önem verildiğini düşündürmektedir. Yeme Farkındalığı birçok yönüyle irdelenen ve sık tartışılan bir konudur. Pintado-Cucarella (2016) çalışmasında yeme farkındalığı skorlarının VKİ, anksiyete ve tıkınırcasına yeme bozukluğu ile ters ilişkili olduğu görülmüştür (29). Yine yeme farkındalığı ölçeğinin kullanıldığı bir diğer çalışmada öz şefkatin yeme farkındalığı skorları ve VKİ ile ilişkili olduğu tespit edilmiştir (30). Bu çalışmalar ışığında kilo kontrolünün sağlanmasında yeme farkındalığı oluşturma ve psikolojik desteğin önemi gitgide artmaktadır. Bu sebeple Tip 2 diyabette kilo kontrolünün ne kadar önemli olduğunu göz önünde bulundurarak sadece obezite de değil aynı zamanda Tip 2 diyabetle mücadele etmeye çalışan grupta da yeme farkındalığı kazandırmak ve yeme farkındalığı durumlarını tespit etmek önem taşımaktadır.

Yeme farkındalığı dürtüsel ve düzensiz beslenme sonucunda sıkça karşılaşılan problemleri azaltmak ve gerekli içgörüyü 
kazanmak için bir firsat sunmaktadır. Diyabet hastalarına yeme farkındalığı kazandırma onların diyet hedeflerine yaklaşmaları ve kendi diyetlerini yönetebilmeleri için iyi bir yol olabilir. Bu çalışmada mevcut durumda diyabet hastalarında yeme farkındalığı azaldıkça AKŞ ve BMI arttığg görülmektedir. Yeme farkındalığ 1 alanı araştırmalarının henüz başlarındadır diyebiliriz. Bu bağlamda diyabet hasta gruplarında yeme farkındalığının kazandırılması ve hastalıkla ilgili parametrelere etkisi üzerine çalışmalara ihtiyaç vardır.

\section{KAYNAKLAR}

1. World Health Statistics 2018: Monitoring health for the SDGs, sustainable development goals. Geneva: World Health Organization; 2018. Licence: CC BY-NCSA 3.0 IGO. (https://apps.who.int/iris/bitstream/hand le/10665/272596/9789241565585-eng.pdf?ua=1, Accessed Date.10.06.2019)

2. Satman I, Omer B, Tutuncu Y, Kalaca S, Gedik S, Dinccag N, Karsidag K, Genc S, Telci A, Canbaz B, Turker F, Yilmaz T, Cakir B, Tuomilehto J. Twelve-year trends in the prevalence and risk factors of diabetes and prediabetes in Turkish adults.; TURDEP-II Study Group. Eur J Epidemiol. 2013;28(2):169-180.

3. Wagenknecht LE, Langefeld CD, Scherzinger AL, Norris JM,Haffner SM, Saad MF, Bergman RN. Insulin sensitivity, insulin secretion, and abdominal fat: The Insulin Resistance Atherosclerosis Study (IRAS) Family Study. Diabetes. 2003; 52: 2490-2496.

4. Smith SR. Obesity: The endocrinology of obesity. Endocrinol Metab Clin North Am. 1996; 25: 921-942.

5. Hasselbaink D, Glatz J, Luiken J, Roemen T, Vusse G. Ketone bodies disturb fatty acid handling in isolated cardiomyocytes derived from control and diabetic rat. Biochem J. 2003; 371:753-760.

6. Doğan B, Yörük N, Öner C, Yavuz G, Oğuz A. Evaluation of diabetes risk and eating habits of university students and personnel. Türk Aile Hekimliği Dergisi. 2017; 21(2):50-55.

7. Arısoy E. Birinci Basamağa Yonelik Tanı ve Tedavi Rehberi. Diabetes Mellitus. Ankara, Sağlık Bakanlığı Yayınları. 2012; 3:271-275.

8. Yılmaz M, Bahceci M, Buyukbese MA. Diabetes Mellitus'un Modern Tedavisi. İstanbul, Turkiye Diabet Vakfı Yayınları 2003; 44- 49.

9. Flegal KM, Graubard BI, Williamson DF, Gail MH. Excess deaths associated with underweight, overweight, and obesity. JAMA. 2005; 293:1861-1867.

10. Knecht S, Ellger T. Obesity in neurobiology. Prog Neurobiol. 2008; 84: 85-103.

11. Framson C, Kristal AR, Schenk JM, Littman AJ, Zeliadt S. Development and validation of the mindful eating questionnaire. J Am Diet Assoc. 2009; 109(8):1439-1444.
12. Beshara M, Hutchinson AD. Does mindfulness matter? Everyday mindfulness, mindful eating and self-reported serving size of energy dense foods among a sample of South Australian adults. Appetite. 2013; 67: 25-29.

13. Hirshmann J, Zaphiropoulos. Kids, carrots, and candy: A practical, positive approach to raising children free of food and weight problems. 2nd ed., United States of America, Creatspace Publisher, 2012. (https://www.academia.edu/39135193/ Kids_Carrots_and_Candy_A_Practical_Positive_Approach_ to_Raising_Children_Free_of_Food_and_Weight_Problems, Accessed Date:20.07.2019).

14. Bishop SR, Lau M, Shapiro S, Carlson L, Anderson ND, Carmody J, Segal ZV, Abbey S, Speca M, Velting D. Mindfulness: A proposed operational definition. Clinical Psychology Science Practice. 2004; 11(3): 230-241.

15. Compare A, Callus E. Mindfulness trait, eating behaviours and body uneasiness: A case- control study of binge eating disorder. Eat Weight Disord. 2012; 17(4):244- 251.

16. Baer RA, Fischer S, Huss DB. Mindfulness and acceptance in the treatment of disordered eating. Journal of RationalEmotive and Cognitive-Behavior Therapy. 2005;23(4):281300.

17. Hulbert-Williams L, Nicholls W, Joy J, Hulbert-Williams N. Initial validation of the Mindful Eating Scale. Mindfulness. 2014; 5(6): 719-729.

18. Lindeman M, Stark K. Emotional eating and eat-ing disorder psychopathology. Eating Disorders. 2001; 9(3):251-259.

19. Köse G, Tayfur M, Birincioğlu İ. Adaptation Study of the Mindful Eating Questionnare (MEQ) into Turkish. Journal of Cognitive-Behavioral Psychotherapy and Research. 2016; 5(3):125-134.

20. Tovote KA, Fleer J, Snippe E. Individual mindfulness-based cognitive therapy and cognitive behavior therapy for treating depressive symptoms in patients with diabetes: Results of a randomized controlled trial. Diabetes Care. 2014;37:24272434.

21. Hartmann M, Kopf S, Kircher C. Sustained effects of a mindfulness-based stress- reduction intervention in type 2 diabetic patients: Design and first results of a randomized controlled trial (the Heidelberger Diabetes and Stress Study). Diabetes Care. 2012;35:945-947.

22. van Son J, Nyklicek I, Pop VJ. The effects of a mindfulnessbased intervention on emotional distress, quality of life and HbAlc in outpatients with diabetes (DiaMind): A randomized controlled trial. Diabetes Care. 2013;36:823-830.

23. Olson KL, Emery CF. Mindfulness and weight loss: A systematic review. Psychosom Med. 2015;77:59-67.

24. Daubenmier J, Kristeller J, Hecht FM. Mindfulness intervention for stress eating to reduce cortisol and abdominal fat among overweight and obese women: An exploratory randomized controlled study. J Obes. 2011;2011:651936.

25. Miller CK, Kristeller JL, Headings A, Nagaraja H. Comparison of a mindful eating intervention to a diabetes self-management intervention among adults with type 2 diabetes: A randomized controlled trial. Health Educ Behav. 2014;12:145-154. 
26. Jordan CH, Wang W, Donatoni L, Meier BP. Mindful eating: Trait and state mindfulness predict healthier eating behavior. Pers Individ Dif. 2014;68:107-111.

27. Forman EM, Shaw JA, Goldstein SP, et al. Mindful decision making and inhibitory control training as complementary means to decrease snack consumption. Appetite. 2016;103:176183.

28. Mantzios M, Wilson JC. Mindfulness, eating behaviours, and obesity: A review and reflection on current findings. Curr Obes Rep. 2015;4:141-146.
29. Pintado-Cucarella S, Rodríguez-Salgado P. Mindful eating and its relationship with body mass index, binge eating, anxiety and negative affect. J Behav, Health Soc Issues. 2016;8(2):1924.

30. Taylor MB, Daiss S, Krietsch K. Associations among selfcompassion, mindful eating, eating disorder symptomatology, and body mass index in college students. Translational Issues in Psychological Science. 2015;1(3):229-238. 